\title{
Molecular Cloning, Characterization, and Expression Regulation of Acyl-CoA Synthetase 6 Gene and Promoter in Common Carp Cyprinus carpio
}

\author{
Dizhi Xie ${ }^{1}$, Zijie He ${ }^{1,2}$, Yewei Dong ${ }^{1}$, Zhiyuan Gong ${ }^{3}$, Guoxing Nie ${ }^{2, *}$ and Yuanyou $\mathrm{Li}^{1, *}$ (D) \\ 1 College of Marine Sciences of South China Agricultural University \& Guangdong Laboratory for Lingnan \\ Modern Agriculture, Guangzhou 510642, China; xiedizhi@scau.edu.cn (D.X.); \\ jie3719@126.com (Z.H.);sunshinewonder@163.com (Y.D.) \\ 2 Laboratory of Aquatic Animal Nutrition and Diet, College of Fisheries, Henan Normal University, \\ Xinxiang 453007, China \\ 3 Department of Biological Sciences, National University of Singapore, Singapore 115473, Singapore; \\ dbsgzy@nus.edu.sg \\ * Correspondence: niegx@htu.cn (G.N.); yyli16@scau.edu.cn (Y.L.)
}

Received: 12 June 2020; Accepted: 28 June 2020; Published: 3 July 2020

\begin{abstract}
Omega-3 long chain polyunsaturated fatty acids (n-3 LC-PUFA), particularly docosahexaenoic acids (22:6n-3, DHA), have positive effects on multiple biologic and pathologic processes. Fish are the major dietary source of n-3 LC-PUFA for humans. Growing evidence supports acyl-coenzyme A (acyl-CoA) synthetase 6 (acsl6) being involved in cellular DHA uptake and lipogenesis in mammals, while its molecular function and regulatory mechanism remain unknown in fish. The present study focused on investigating the molecular characterization and transcription regulation of the acsl6 gene in the freshwater teleost common carp (Cyprinus carpio). First, the full length of acsl6 cDNA contained a coding region of $2148 \mathrm{bp}$ for 715 amino acids, which possessed all characteristic features of the acyl-CoA synthetase (ACSL) family. Its mRNA expression was the highest in the brain, followed by in the heart, liver, kidney, muscle, and eyes, but little expression was detected in the ovary and gills. Additionally, a candidate acsl6 promoter region of $2058 \mathrm{bp}$ was cloned, and the sequence from $-758 \mathrm{bp}$ to $-198 \mathrm{bp}$ was determined as core a promoter by equal progressive deletion and electrophoretic mobility shift assay. The binding sites for important transcription factors (TFs), including stimulatory protein 1 (SP1), CCAAT enhancer-binding protein $(\mathrm{C} / \mathrm{EBP} \alpha)$, sterol-regulatory element binding protein 1c (SREBP1c), peroxisome proliferator activated receptor $\alpha(\operatorname{PPAR} \alpha)$, and PPAR $\gamma$ were identified in the core promoter by site-directed mutation and functional assays. Furthermore, the intraperitoneal injection of PPAR $\gamma$ agonists (balaglitazone) increased the expression of acsl6 mRNA, coupling with an increased proportion of DHA in the muscle, while opposite results were obtained in the injection of the SREBP1c antagonist (betulin). However, the expression of acsl6 and DHA content in muscle were largely unchanged by PPAR $\alpha$ agonist (fenofibrate) treatment. These results indicated that acsl6 may play an important role for the muscular DHA uptake and deposition in common carp, and PPAR $\gamma$ and SREBP-1c are the potential TFs involved in the transcriptional regulation of acsl6 gene. To our knowledge, this is the first report of the characterization of acsl6 gene and its promoter in teleosts.
\end{abstract}

Keywords: acyl-CoA synthetase 6; transcriptional regulation; DHA deposition; Cyprinus carpio

\section{Introduction}

Omega-3 long chain polyunsaturated fatty acids (n-3 LC-PUFAs), particularly eicosapentaenoic acid (EPA; 20:5n-3) and docosahexaenoic acids (22:6n-3, DHA), have positive effects on multiple 
biologic and pathologic processes including metabolic disorders, cardiovascular and neurological diseases, cancer, inflammation, and pain [1-5]. Biosynthesis of n-3 LC-PUFAs is from $\alpha$-linolenic acid (ALA, 18:3n-3) substrates, but ALA is limited (less than 4\%) in humans; hence, the minimum recommended intake of EPA and DHA is $0.2-0.45 \mathrm{~g}$ per day [1,6]. It is well known that the benefits of food fish are to provide n-3 LC-PUFAs in diets, while with wild fish resources declining, the major source of n-3 LC-PUFAs has turned to cultured fish [7]. To date, the available plant lipid sources (without LC-PUFAs but rich in C18 PUFAs) are widely applied in aquaculture to reduce the fish oil (rich in LC-PUFA) dependence and feeding cost, while these lipids reduce the muscular n-3 LC-PUFA level (especial for the DHA level) in tested fish species and greatly affect the nutritional quality of cultured fish [8]. To efficiently use plant-based alternatives and to maximize endogenous n-3 LC-PUFA biosynthesis, much attention has been focused on illuminating the regulation mechanisms of LC-PUFA biosynthesis in teleosts [9-12]. However, it is still unclear about the n-3 LC-PUFA deposition process and its regulatory mechanism in fish muscle.

It has been reported in mammals that LC-PUFAs are desorbed and diffused into cells through protein-mediated transport mechanisms, such as fatty acid translocase (FAT/CD36), fatty acid transport protein (FATPs) and plasma membrane fatty acid binding protein (FABPpm) [13-15]. Similar to the FATPs above, the long-chain acyl-coenzyme A (acyl-CoA) synthetase (ACSL) family, including Acsl1-6, has also been shown to accelerate fatty acid uptake through influencing the cellular fatty acid metabolism in peripheral tissues and cells $[16,17]$. ACSL enzymes play an important role in lipid metabolism, since these enzymes activate long chain fatty acid (LCFA, with 12-22 carbons) to form acyl-CoAs, which is subsequently used in almost all catabolic and anabolic downstream pathways of FA metabolism $[16,17]$. Additionally, five distinct ACSL genes differing in their substrate preferences have been identified in mammals. Recent studies prove that acsl6 is required to specifically enrich DHA in the mouse brain and that the acsl6 mutant $\left(a c s l 6^{-/-}\right)$has a significant decrease in brain DHA level [18-20]. Acsl6 is also involved in the selective enrichment of DHA-containing membrane phospholipids in differentiating spermatids and seminiferous tubules, thus supporting its role in normal spermatogenesis in mice [21,22]. Moreover, overexpression of acsl6 stimulates the biosynthesis of phospholipid and triglycerides and decreases the mitochondrial oxidative capacity in mammalian skeletal muscle $[23,24]$. Thus, these mammal data could provide clues for studying the function of acsl6 in the DHA deposition in fish muscle.

Common carp (Cyprinus carpio) is one of the most important cultured freshwater fish in the world, especially in China, and over 4 million tons are produced annually [25]. However, the muscular DHA content in farmed common carp was significantly lower than that in the wild fish [26,27]. To explore the molecular mechanism of DHA deposition in common carp muscle, the present study was focused on investigating the molecular characterization and the transcription regulation of the acsl6 gene. First, the full-length cDNA of the acsl6 gene and its candidate promoter were cloned. Second, key elements in the core promoter region were identified by the targeted mutation of potential binding sites of selected key transcriptional factors (TFs). Finally, agonist/antagonist injection was performed to identify the roles of key TFs. These results should provide novel insights into the regulatory mechanisms of muscular DHA deposition in fish.

\section{Results}

\subsection{Sequence and Phylogenetic Analyses of Common Carp acsl6 cDNA}

A cDNA (3643 bp) of common carp acsl6 was obtained, including a $5^{\prime}$-untranslated region (UTR) (214 bp), a full-length coding region (2148 bp) encoding 715 amino acids (GenBank accession no. MT431660), and a 3'-UTR (1420 bp) (Figure S1). The deduced protein sequence possessed all typical active site residues of ACSL, including adenosine monophosphate monophosphate (AMP) binding sites, CoA binding site, and acyl-activating enzyme consensus motif, as well as a gate domain with D-x4-(F, Y)-LPLAH-x2-E and a linker motif with GD-x13-DR-x4 (Figure 1), which has been well 
conserved in common carp and other fish species possessing acsl6, includeing Epinephelus lanceolatus, Nothobranchius furzeri, Oreochromis niloticus, Salmo solar, Carassius auratus, and Danio rerio (Figure 1).

A neighbor-joining phylogenic tree was constructed based on the deduced acsl6 amnio acid sequences from fish and other vertebrates. Phylogenetic analysis revealed that acsl6 was divisible into four main clusters, including fish, birds, amphibians, and mammals (Figure 2). The common carp acsl6 was grouped with orthologues from other teleost species and more distantly to other vertebrates, and it was clustered most closely to C. auratus (Figure 2).

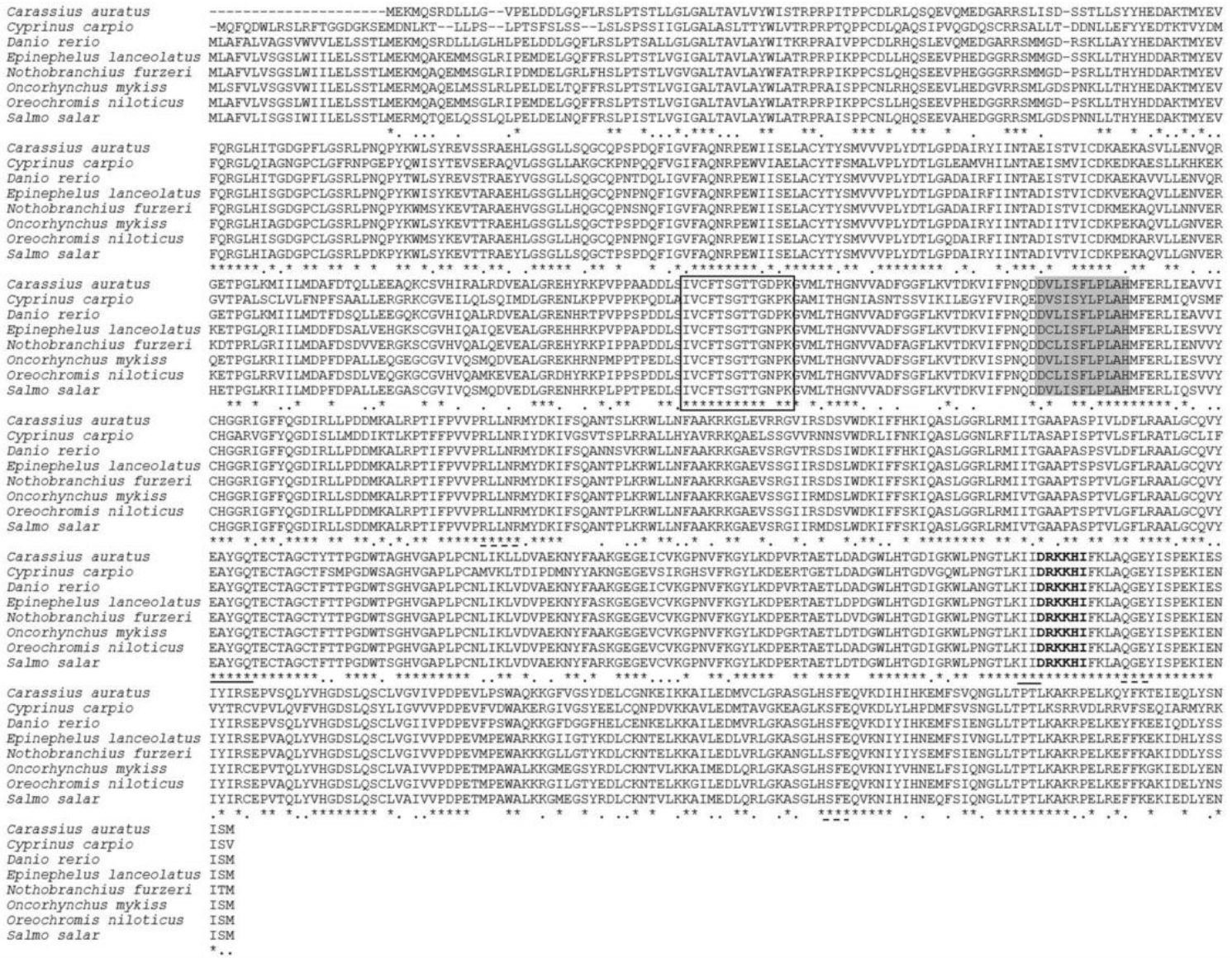

Figure 1. Alignment of the deduced amino acid (aa) sequences of acsl6 isolated from Cyprinus carpio with other orthologues, including Carassius auratus (XP_026089889.1), Danio rerio (XP_021324602.1), Epinephelus lanceolatus (XP_033505573.1), Nothobranchius furzeri (XP_015816936.1), Oncorhyncus mykiss (XP_021479764.1), Oreochromis niloticus (XP_003451433.2), and Salmo salar (XP_014053481.1): Deduced aa sequences were aligned using ClustalW2. Identical and similar residues are marked with * and:, respectively. The conserved acyl-activating enzyme (AAE) motif is a black box, the gate domain is shaded, two putative CoA binding sites are dash-underlined, the two putative AMP binding sites are solid underlined, and the linker domain is represented with bold. 


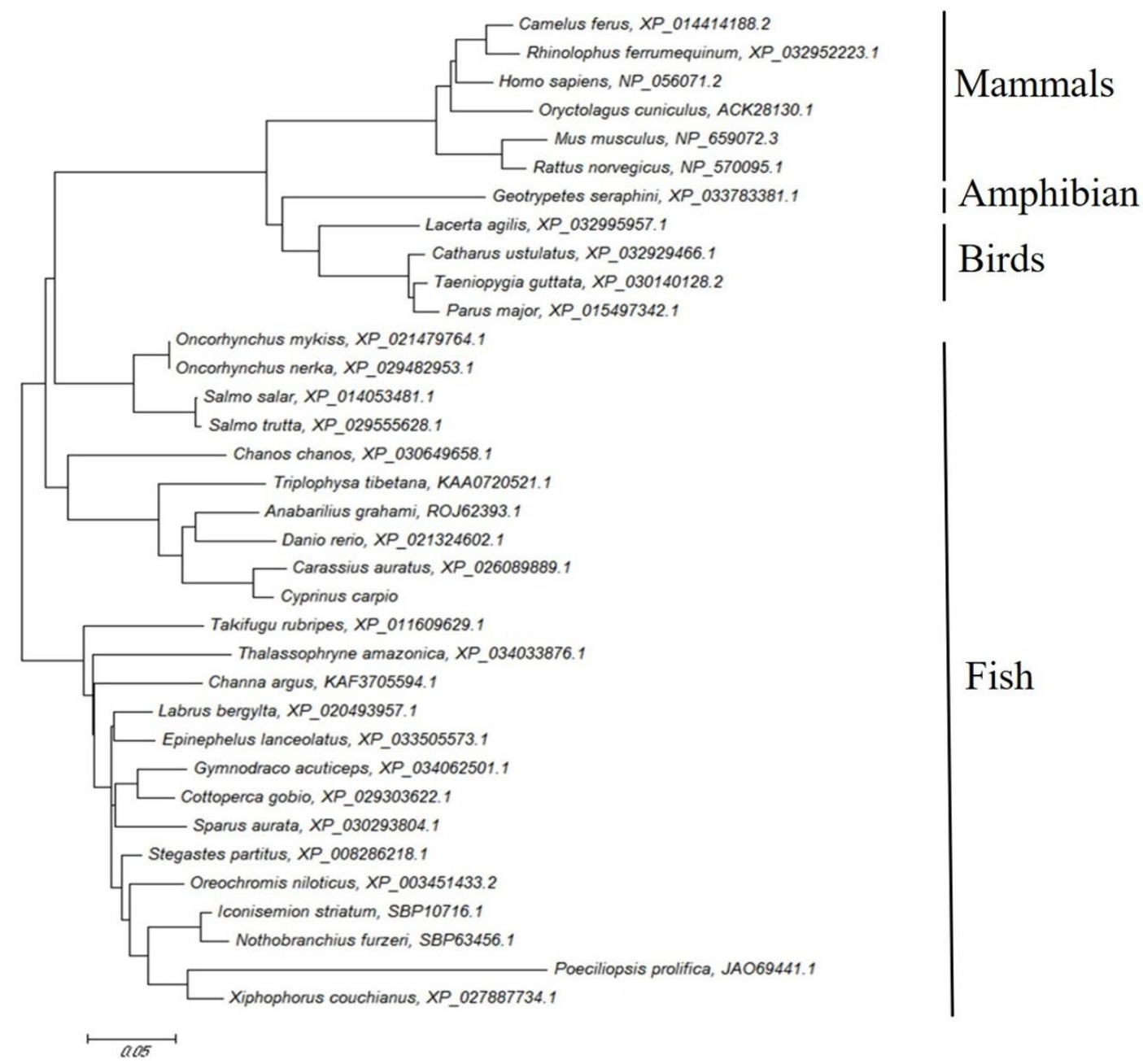

Figure 2. Phylogenetic analysis of acsl6 from different animal species: The tree is based on an alignment corresponding to full-length amino acid sequences using ClustalW and MEGA (5.0). The number denote the bootstrap majority consensus values from 1000 replicates.

\subsection{Tissue Distribution of the Common Carp acsl6}

RT-PCR and qPCR were used to analyze acsl6 mRNA expression of in different common carp tissues (Figure 3A,B). The transcript of acsl6 was detected in the brain, eyes, heart, liver, kidney, spleen, red muscle, white muscle, mesenteric fat, anterior intestine, middle intestine, and hind intestine but not in the gills and ovary (Figure 3A), with apparent higher expression levels in brain compared to the other tissues (Figure 3B). 


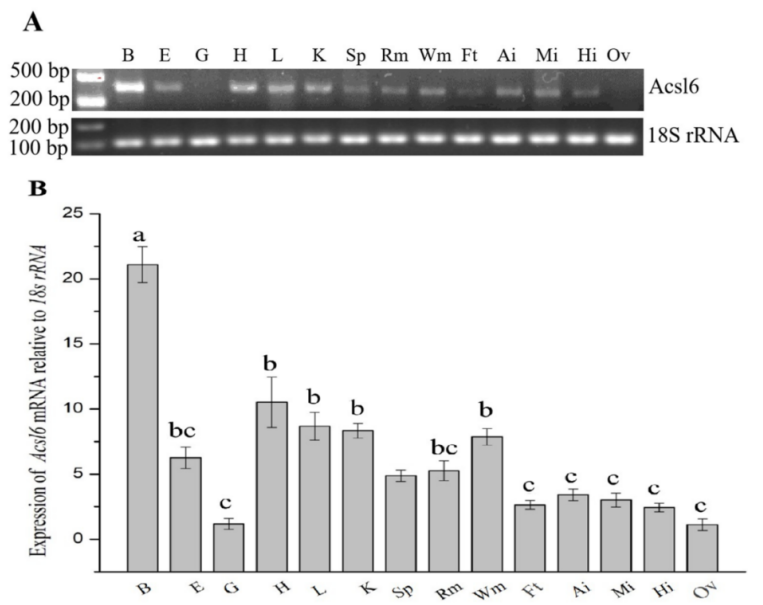

Figure 3. Semi-quantitative RT-PCR (A) and real-time quantitative PCR (B) analyses of acsl6 mRNA expression: Expression values were normalized to those of $18 \mathrm{~S}$ rRNA. Data are means $\pm \operatorname{SEM}(n=3)$. Bars not sharing a common letter indicated significant differences $(p<0.05)$ as determined by one-way ANOVA followed by Tukey's multiple comparison test. Abbreviations: B, brain; E, eye; G, gill; H, heart; $\mathrm{L}$, liver; K, kidney; Sp, spleen; Rm, red muscle; Wm, white muscle; Ft, mesenteric fat; Ai, anterior intestine; $\mathrm{Mi}$, middle intestine; $\mathrm{Hi}$, hind intestine; and $\mathrm{Ov}$, ovary.

\subsection{The Structural Features of Common Carp acsl6 Gene Promoter}

A 2058-bp candidate promoter of the acsl6 gene was cloned in this study. Schematic diagram and sequence of the acsl6 promoter are shown in Figure 4 and Figure S2, respectively. It includes $1790 \mathrm{bp}$ of upstream nontranscribed sequence and $214 \mathrm{bp} 5^{\prime}$-UTR. To determine the core promoter region of the acsl6 gene, the full length of candidate promoter (SD1) and its $5^{\prime}$ serial truncations (SD2-SD4) were fused to a luciferase reporter vector pGL3.0 and tested for their ability to mediate transcription. Among the four promoter constructs, SD3 showed the maximal promoter activity. As SD4 had a significant decrease of promoter activity compared to SD3 (Figure 4), the region between SD4 to SD3 ( $-758 \mathrm{bp}$ to $-198 \mathrm{bp}$ ) was identified as the core regulatory region of the common carp acsl6 promoter, and the sequence of this fragment was used for further functional analysis.

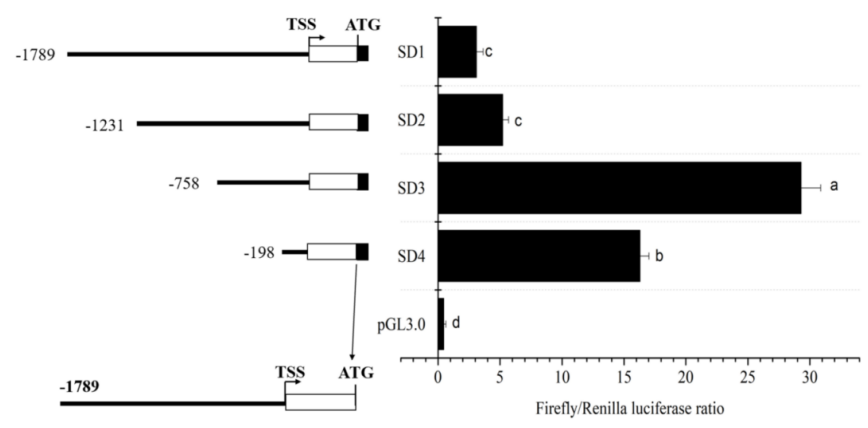

Figure 4. Structure and progressive deletion analysis of grouper acsl6 promoter: $5^{\prime}$ deletion constructs are shown on the upper left, and the structure of acsl6 promoter is showed on the lower left. Noncoding exons are indicated with open boxes, and luciferase coding frames are indicated by closed boxes. The sequence is numbered relative to the first base of the transcription start site (TSS), assumed to be the first base of the $5^{\prime}$ noncoding exon. Promoter activity of constructs is represented on the right with the values representing normalized activity (Firefly luciferase-Renilla luciferase). Bars not sharing a common letter indicated significant differences $(p<0.05)$ among deletions determined by one-way ANOVA followed by Tukey's multiple comparison test. 


\subsection{Demonstration of Binding of Muscle Nucleus Proteins to the Core Regulatory Region by EMSA}

To further confirm whether the core regulatory regions of the acsl6 promoter provides binding sites for potential TFs. Electrophoretic mobility shift assay (EMSA) was performed with muscular cytoplasmic and nuclear proteins. As shown in Figure 5, a gel shift band was observed only in lane 3 with nucleus proteins and $5^{\prime}$ biotin labeled probe, which indicated an interaction between nucleus proteins and the core regulatory region of acsl6 (Figure 5). There was no gel shift band in other lanes, such as lane 1 without proteins; lane 2 with cytoplasmic proteins; or lane 4 with nucleus proteins, an unlabeled competitor probe, and a $5^{\prime}$ biotin labeled probe. These results indicated that some nucleus proteins in muscle could bind to the core promoter of common carp acsl6.

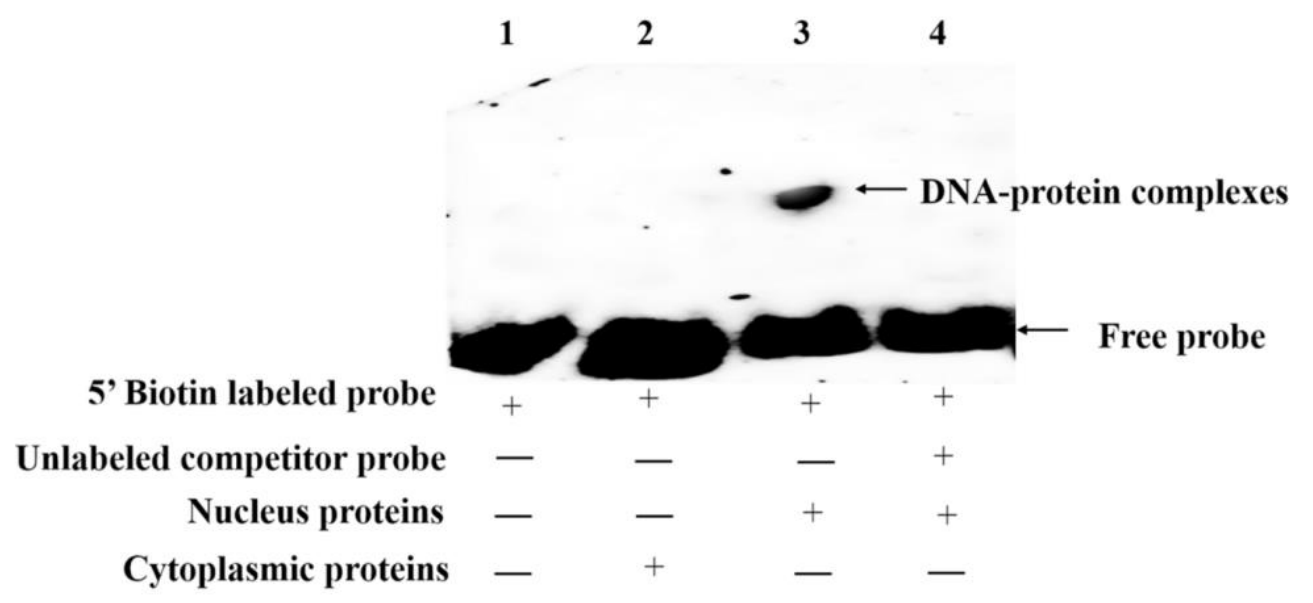

Figure 5. Electrophoretic mobility shift assay (EMSA) of the common carp acsl6 core promoter with muscular nuclear proteins: Each lane is represented as lane 1 (no proteins, $5^{\prime}$ biotin labeled probe), lane 2 (muscular cytoplasmic protein and $5^{\prime}$ biotin labeled free probe), lane 3 (muscular nucleoprotein and $5^{\prime}$ biotin labeled free probe), and lane 4 (muscular nucleoprotein, unlabeled competitor probe, and $5^{\prime}$ biotin labeled free probe). " + " means that the corresponding material in the row has been added, and "-" means that the material is not added.

\subsection{Identification of Cis-Acting Elements in the Core Regulatory Region of Promoter}

Bioinformatics analysis of the core regulatory region of the common carp acsl6 promoter indicated that there are eleven predicted TF binding sites including forkhead transcription factor 1 (FOXO1), stimulatory protein 1 (SP1), activated protein 1 (AP1), caudal type homeobox transcription factor 1 (CDX1), Yin Yang 1 (YY1), CCAAT enhancer binding protein $(\mathrm{C} / \mathrm{EBP} \alpha)$, TATA box binding protein (TBP), sterol-regulatory element binding protein 1c (SREBP1c), peroxisome proliferator activated receptor $\alpha$ (PPAR $\alpha$ ), and PPAR $\gamma$ (Figure 6). Also, these eleven predicted TF binding sites were mutated and transfected into Human embryonic kidney cell line (HEK 293T) cells for determining the effects on transcriptional activity. Compared with wild type SD3, mutation of TF binding sites for PPAR $\gamma$, PPAR $\alpha$, and SREBP1c resulted in the most decreased transcriptional activity $(p<0.05)$, followed by SP1 and C/EBP $\alpha$ (Figure 7), which suggested that these TF binding sites were very important for maintaining the acsl6 promoter activity. 


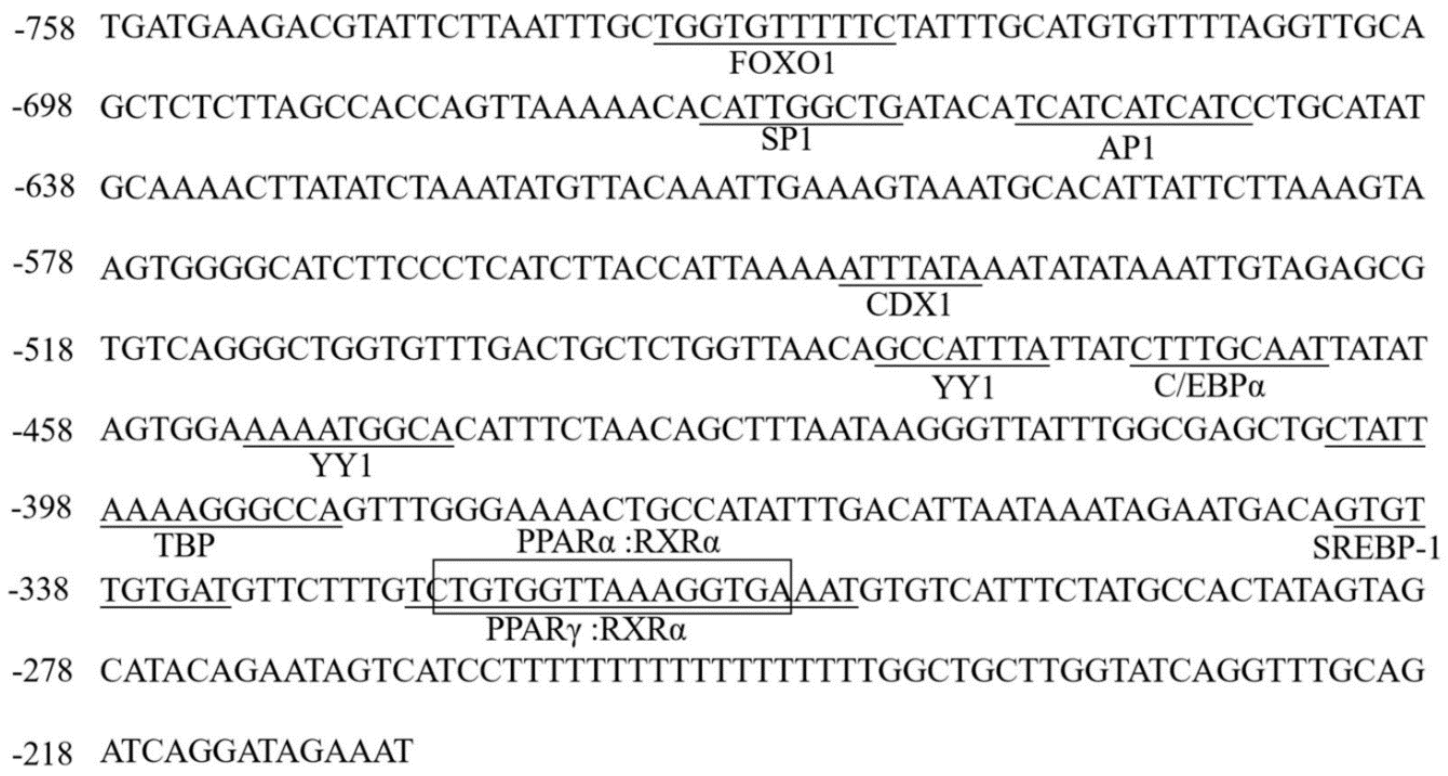

Figure 6. The nucleotide sequence and predicted binding sites for transcription factors in the core region of common carp acsl6 promoter: Numbers are given relative to the first base of the transcription start site (TSS). Potential transcription binding motifs are marked in underline and open boxes for PPAR $\alpha$ : RXR $\alpha$. Details for the name of transcription factors are shown in the text.

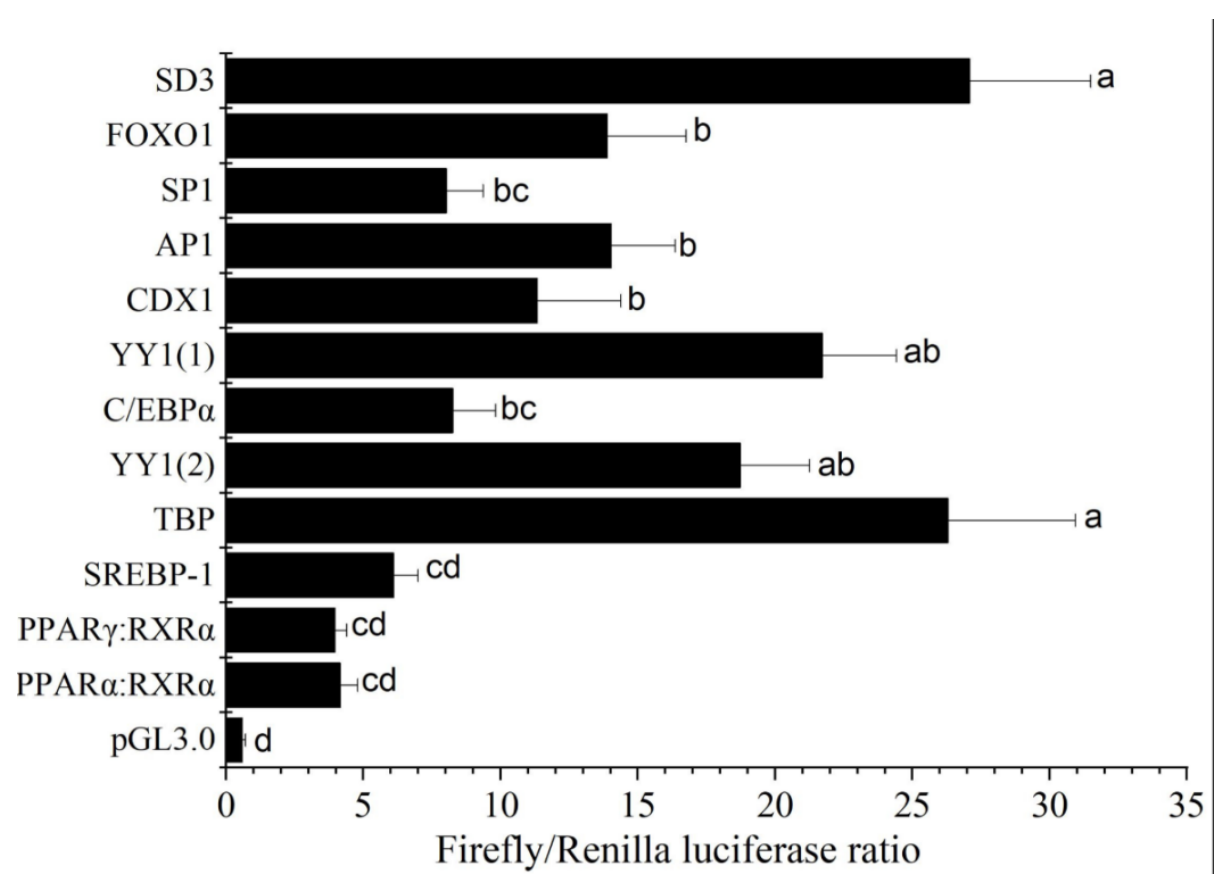

Figure 7. The effects of site-directed mutation of transcription factor binding sites on the promoter activity of common carp acsl6 gene: Mutations of promoter deletion on SD3 (wild type, -758 to ATG) were generated according to in silico predications as shown in Figure 4, and the effects of mutation on promoter activity were compared with SD3. Promoter activity of constructs is represented on the right with the values representing normalized activity (Firefly luciferase-Renilla luciferase). Bars not sharing a common letter indicated significant differences $(p<0.05)$ among deletions determined by one-way ANOVA followed by Tukey's multiple comparison test. 


\subsection{Effects of TFs Agonists/Antagonist on TFs and acsl6 Expression and Fatty Acid Composition in Muscle}

To further confirm the regulatory role of PPAR $\gamma$, PPAR $\alpha$, and SREBP1 on acsl6 expression, PPAR $\alpha$ agonist fenofibrate, PPAR $\gamma$ agonist balaglitazone, or SREBP1c antagonist betulin were injected into the enterocoelia of juvenile common carp. The results of qPCR showed that the muscular ppar $\gamma$ and acsl6 mRNA levels significantly increased in balaglitazone treatment groups compared to the dimethyl sulfoxide (DMSO) group (control), and muscular srebp1 and acsl6 mRNA levels were significantly downregulated by antagonist betulin $(p<0.05)$ (Figure 8). Although the muscular level of the ppar $\alpha$ mRNA expression level was upregulated by fenofibrate $(p<0.05)$, acsl6 mRNA levels showed no significant difference between the fenofibrate group and the control group $(p>0.05)$ (Figure 8).
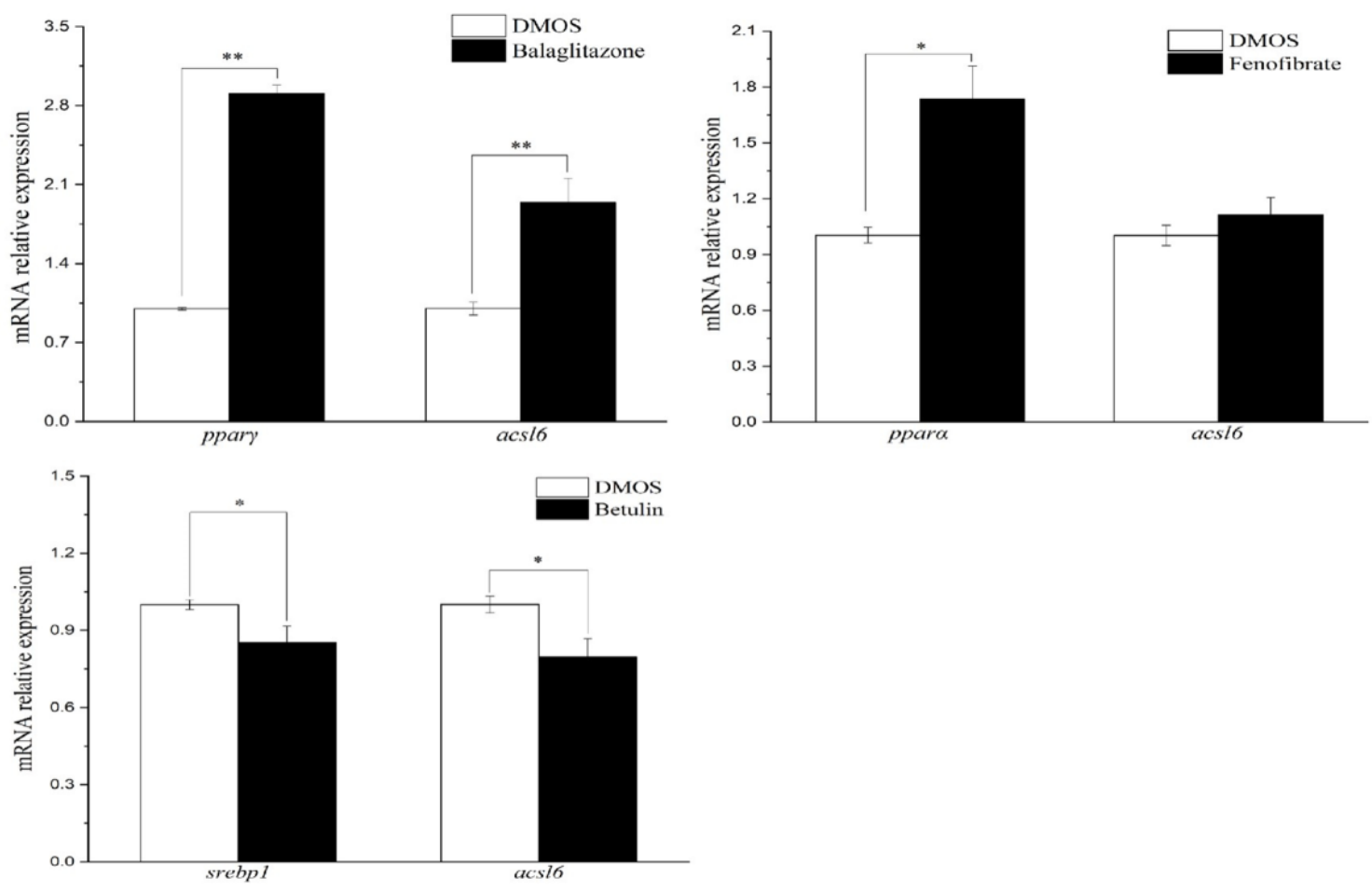

Figure 8. Q-PCR analysis of acsl6, ppara, ppar $\gamma$, and srebp1 mRNA expression levels in the muscle of juvenile common carp injected with Ppar $\alpha$ agonist (fenofibrate), Ppar $\gamma$ agonist (balaglitazone), Srebp1 antagonist (betulin), or control (dimethyl sulfoxide (DMSO)). Results are means \pm SEM $(n=3)$. Significant differences compared between the injected treatments (fenofibrate, balaglitazone, and betulin), and corresponding control group were analyzed using Student's $t$-test, with * denoting $p<0.05$ and with ${ }^{* *}$ denoting $p<0.01$.

Moreover, the results of fatty acid composition in muscle showed that there was a higher content of DHA in the balaglitazone group compared with that in the control group $(p<0.05)$ while the content of DHA in fenofibrate treatment was comparable with that in the control group (Table 1). Comparing with the control group, the muscular DHA, ARA, and 18:3n-6 were significantly decreased in the betulin group $(p<0.05)$ (Table 1$)$. 
Table 1. Main fatty acids composition in muscle of common carp injected with siRNA, agonists (balaglitazone and fenofibrate), and antagonist (betulin) (\% area).

\begin{tabular}{ccccc}
\hline \multirow{2}{*}{ Main Fatty Acids } & \multicolumn{4}{c}{ Injected Treatments } \\
\cline { 2 - 5 } & DMSO & Fenofibrate & Balaglitazone & Betulin \\
\hline $16: 0$ & $13.10 \pm 0.68$ & $11.92 \pm 1.78$ & $12.22 \pm 2.32$ & $14.73 \pm 1.51$ \\
$18: 0$ & $1.54 \pm 0.05$ & $1.11 \pm 0.07^{*}$ & $1.05 \pm 0.05^{*}$ & $1.93 \pm 0.07^{*}$ \\
$20: 0$ & $0.28 \pm 0.03$ & $0.21 \pm 0.02$ & $0.25 \pm 0.02$ & $0.23 \pm 0.01$ \\
$16: 1$ & $1.99 \pm 0.18$ & $2.10 \pm 0.37$ & $2.13 \pm 0.17$ & $2.31 \pm 0.29$ \\
$18: 1$ & $25.13 \pm 1.44$ & $21.81 \pm 3.11$ & $23.25 \pm 3.15$ & $27.49 \pm 4.06$ \\
$18: 2 n-6$ & $32.92 \pm 3.54$ & $33.92 \pm 3.51$ & $31.97 \pm 2.13$ & $34.11 \pm 2.34$ \\
$18: 3 n-6$ & $0.23 \pm 0.05$ & $0.28 \pm 0.10$ & $0.27 \pm 0.04$ & $0.13 \pm 0.01^{*}$ \\
20:4n-6 (ARA) & $1.54 \pm 0.03$ & $1.55 \pm 0.22$ & $1.63 \pm 0.06$ & $1.38 \pm 0.10^{*}$ \\
18:3n-3 & $5.21 \pm 0.02$ & $4.93 \pm 0.02$ & $4.85 \pm 0.01$ & $5.16 \pm 0.02$ \\
18:4n-3 & $0.43 \pm 0.10$ & $0.40 \pm 0.04$ & $0.44 \pm 0.03$ & $0.35 \pm 0.01$ \\
20:5n-3 (EPA) & $0.43 \pm 0.03$ & $0.41 \pm 0.02$ & $0.48 \pm 0.03$ & $0.39 \pm 0.01$ \\
22:6n-3 (DHA) & $2.27 \pm 0.10$ & $2.28 \pm 0.13$ & $2.53 \pm 0.07^{*}$ & $1.81 \pm 0.11^{*}$ \\
\hline
\end{tabular}

Results are means \pm SEM $(n=3)$. Significant differences compared between the injected treatments (fenofibrate, balaglitazone, and betulin) and corresponding control group were analyzed using Student's t-test, with * denoting $p<0.05$.

\section{Discussion}

Several members of the ACSL family catalyze a wide range of fatty acids to form acyl-CoAs with some substrate preferences toward different FA metabolic fates [16]. To date, ACSL1, ACSL3, and ACSL4 have well been identified in numerous species, while acsl6 has only been identified in rat, human, and mouse [16,28-30]. Several TFs, such as Sp1, LXR, SREBP, and PPAR $\gamma$, contributing to the control and regulation of ACSL1, ACSL3, and ACSL4, have also been characterized in mammals [31-35]. In this study, the molecular characterization, tissue distribution, and transcriptional regulation of common carp acsl 6 were investigated and, here, provided evidences for the function of SREBP1 and PPAR $\gamma$ on acsl6 expression and muscular DHA content in fish.

The present study represents the first characterization of acsl6 cDNA in fish. The predicted common carp acsl6 peptide possesses highly conserved residues of the ACSL family including the two well characterized domains, the gate and linker domains $[36,37]$. The gate domain (D-x4-(F, Y)-LPLAH-x2-E) contains an entry gate for the long chain fatty acid substrate [36,37]. The linker domain (GD-x13-DR-x4) of ACSL contains an ASP (D) residue, while a Gly (G) residue in that of short and medium ACS [38]. The overall tree branching pattern of acsl6 indicated that the vertebrate acsl6 sequence was divisible into four clades and that the common carp acsl6 peptide was highly similar to other acsl6 peptides from teleosts (Figure 2). This is in accordance with the recent finding that ACSL proteins have been highly conserved throughout evolution [17].

The gene expression pattern indicates its functional diversification in the tissue to some extent. In mammals, acsl6 has a fairly restricted expression pattern but is highly expressed in brain and gonad $[17,30]$ and has been suggested to be important and specific for DHA uptake in brain, differentiating spermatids, and seminiferous tubules [18-22]. Compared to mammals, a relatively widespread distribution pattern was observed in common carp acsl6 mRNA, which showed the highest expression level in the brain and weaker expressions in the heart, liver, kidney, muscle, and eye but no expression in the ovary. This is similar to the tissue distribution obtained from zebrafish, in which the mRNA level of acsl6 was greatest in the brain, followed by other tissues (eye, heart, testis, and kidney) and no expression in the ovary [17]. Between fish and mammals, the differences in tissue distribution of acsl6 possibly reflected the functional importance of DHA for these tissues [2,22] and the high content of DHA in fish [7].

It is well known that the spatiotemporal expression pattern of gene expression is dependent on the binding of transcription factors to specific sequences in gene promoters [39]. In this study, a 2058-bp acsl6 candidate promoter was also cloned from common carp and it included $1790 \mathrm{bp}$ of upstream nontranscribed sequences and $214 \mathrm{bp}$ of 5'-UTR without intron (Figure 4). Previously, mammal acsl6 gene promoters had been reported in mice, which includes $2102 \mathrm{bp}$ of upstream nontranscribed 
sequences and $443 \mathrm{bp}$ of $5^{\prime}$-UTR with $334 \mathrm{bp}$ introns [30]. The unidirectional deletion analysis showed that the upstream region of $-2102 \mathrm{bp}$ to $+45 \mathrm{bp}$ exerts a negative regulatory function to control mouse acsl6 promoter activity [30] while the negative regulatory region of common carp acsl6 promoter was located between $-1789 \mathrm{bp}$ and $-758 \mathrm{bp}$. These above results suggested that the shorter negative regulatory region may contribute to the relatively widespread distribution pattern of the common carp acsl6 gene. Based on progressive deletion, the core region of the common carp acsl6 promoter was -758 to -198 (Figure 4). Additionally, the verification of EMSA also indicated that some muscular nucleus proteins could bind to the core promoter of common carp acsl6 (Figure 5), while the core promoter of mouse acsl6 was in the proximal promoter $(+339$ to +412$)$ [30].

The mouse acsl6 core promoter has been shown to contain binding sites for transcription factors AP2, SP1, C/EBPa, C/EBPb, CREB, and NF-1 [30]. Here, we showed that the common carp acsl6 promoter shared the same binding sites for SP1 and C/EBP $\alpha$. Site-directed mutagenesis revealed that cis-elements such as SREBP1c, PPAR $\alpha$, and PPAR $\gamma$ were essential in driving the activity of the common carp acsl6 promoter (Figure 7), which was consistent with the activation of PPAR $\alpha$, PPAR $\gamma$, and SREBP1c for mammalian Acsl1 and Acsl5 transcription, respectively [40,41]. Moreover, Motallebipour et al. [42] found that an SREBP-1 binding site was located in the first intron of the human ASCL6 gene promoter. Those results indicated that the SRE and PPAR elements could also be essential in driving acsl6 promoter activity in fish.

We also found that the PPAR $\gamma$ agonist (balaglitazone) induced ppar $\gamma$ expression and simultaneously increased the expression of acsl6 in muscle; in contrast, the SREBP1c antagonist (betulin) decreased the expression of $a c s l 6$, coinciding with the suppression of srebp1c expression (Figure 8). These results suggested a possible regulation of PPAR $\gamma$ and SREBP-1c on common carp acsl6 expression. Although transcriptional control of the acsl6 has not been well studied, transcriptional studies of another ACSL family indicated that the PPAR $\gamma$ agonist increased mammal Acsl5 and Acsl1 mRNA expression in the adipose and muscle tissue $[43,44]$. Hepatic Acsl5 expression increased by SREBP-1c overexpression in transgenic mammals and hepatocytes [40,45]. These studies implied that PPAR $\gamma$ and SREBP-1c are common TFs for the ACSL family. The positive regulation of acsl6 by TFs eventually embodied the changing products of the acsl6 enzyme. Accordingly, in the present study, it was clearly shown that increased DHA concentrations of muscle were associated with the treatment of PPAR $\gamma$ agonist while the muscular DHA levels were decreased by SREBP1c antagonist treatment. In mammals, growing evidence supports a role for the acsl6 in cellular DHA uptake [18-22] and muscular lipogenesis [23]. Collectively, these observations suggested that acsl6 probably promotes muscular DHA uptake and deposition in common carp, which are subject to the regulation of PPAR $\gamma$ and SREBP-1c.

In conclusion, the present study has described the cloning and molecular characterization of the acsl 6 cDNA and promoter from common carp. Moreover, PPAR $\gamma$ and SREBP-1c were identified as the potential TFs for acsl6 gene transcription in vertebrates for the first time. The results might contribute to the exploration of enhancing muscular n-3 LC-PUFA contents in farmed fish. Compared with wild fish, farmed fish decreased the chance of acquiring dietary DHA by formula feed with plant lipid sources. The dietary fatty acid compositions may also affect the acsl6 expression, which further reduce the DHA content in farmed fish. Thus, further studies seem necessary to investigate the nutritional regulation of acsl6 expression.

\section{Materials and Methods}

\subsection{Ethics Statement}

All fish procedures were performed following the National Institutes of Health guide for the care and use of laboratory animals (NIH Publications No. 8023, revised 1978) and approved by the Institutional Animal Care and Use Committee of the South China Agricultural University (SCAU-AEC-2010-0416, approved on 18 June 2018). All the fish surgeries were performed with $0.01 \%$ 2-phenoxyethanol (Sigma-Aldrich, St. Louis, MO, USA) anesthesia to minimize suffering. 


\subsection{Fish and Tissue Collection}

Common carp juveniles (about $13.0 \mathrm{~g}$ ) were purchased from a commercial aquafarm (Guangzhou, China). Before experiments, all fish were acclimated to the experimental conditions by feeding with a formula feed (32\% crude protein, $8 \%$ crude lipid) for two weeks. The formulations and proximate and fatty acid compositions of diets are presented in Tables S1 and S2 of our previous study [46]. For determining the tissue distribution of acsl6 transcripts, tissue samples including eye, brain, gill, heart, liver, spleen, kidney, red/white muscle, mesenteric fat, anterior intestine, middle intestine, hind intestine, and ovary were collected from three fish. Tissue samples were frozen in liquid nitrogen immediately after collection and stored at $-80^{\circ} \mathrm{C}$ until analysis.

\subsection{Cloning of acsl6 cDNA}

Total RNA was extracted and mixed from common carp brain, liver, and muscle using Trizol reagent (Invitrogen, USA), and the first-strand cDNA was synthesised using Cloned AMV First-Strand cDNA Synthesis kit (Invitrogen, Carlsbad, CA, USA). To amplify the first fragment of acsl6 cDNA, specific primers (acsl6-F1 and acsl6-R1, Table 1) were designed based on the common carp muscular transcriptome (unpublished data). PCR was performed using an RT-PCR kit from Invitrogen (Carlsbad, CA, USA) with an amplification program consisting of an initial denaturation at $94{ }^{\circ} \mathrm{C}$ for $3 \mathrm{~min}$, followed by 30 cycles of denaturation at $94{ }^{\circ} \mathrm{C}$ for $30 \mathrm{~s}$, annealing at $56^{\circ} \mathrm{C}$ for $45 \mathrm{~s}$ and extension at $72{ }^{\circ} \mathrm{C}$ for $3 \mathrm{~min}$, and a final extension at $72{ }^{\circ} \mathrm{C}$ for $10 \mathrm{~min}$. The positive PCR fragments were confirmed by DNA sequencing (Shanghai Sangon Biotech Co., Ltd., China). Following this, the cDNA ends of the acsl6 gene were obtained by $5^{\prime}$ and $3^{\prime}$ rapid amplification of cDNA ends using Gene Racer ${ }^{\mathrm{TM}} \mathrm{Kit}$ (Invitrogen, Carlsbad, CA, USA) with gene-specific primers (acsl6-R2/acsl6-R3 and acsl6-F2/acsl6-F3, Table 2).

\subsection{Sequence and Phylogenetic Analysis of acsl6}

The deduced amino acid (aa) sequence of the newly cloned common carp acsl6 cDNA was aligned with acsl6 orthologues from other fish species, Carassius auratus (XP_026089889.1), Danio rerio (XP_021324602.1), Epinephelus lanceolatus (XP_033505573.1), Nothobranchius furzeri (XP_015816936.1), Oncorhyncus mykiss (XP_021479764.1), Oreochromis niloticus (XP_003451433.2), and Salmo salar (XP_014053481.1) by using ClustalW2. Multiple alignments of the corresponding acsl6 aa sequence were performed using the EMBOSS Needle Pairwise Sequence Alignment tool (http://www.ebi.ac. uk/Tools/psa/emboss_needle/). The phylogenetic tree of acsl6 from a variety of vertebrate lineages was constructed with the neighbor-joining method [47]. Confidence in the resulting phylogenetic tree branch topology was bootstrapped with 10,000 iterations.

\subsection{Tissue Distribution of acsl6 Transcripts}

The distributions of acsl6 transcripts were measured in different tissues by reverse transcription PCR (RT-PCR) and real-time quantitative PCR (qPCR) analysis. Total RNAs from the brain, eyes, gills, heart, liver, kidney, spleen, red/white muscles, mesenteric adipose, anterior intestine, middle intestine, hind intestine, and ovary were extracted as described above, and $1 \mu \mathrm{g}$ of RNA was reverse-transcribed into cDNA. RT-PCR was performed as described above. Additionally, qPCR was performed with a Lightcycler 480 system (Roche, Basel, Switzerland). The amplification was performed in $20 \mu \mathrm{L}$ reaction system containing $5 \mu \mathrm{L}$ of SYBR Premix, $0.5 \mu \mathrm{L}$ of each primer $(10 \mu \mathrm{M}), 3 \mu \mathrm{L}$ RNase free water, and $1 \mu \mathrm{L}$ of cDNA. The real-time RT-PCR program was a two-step method: 1 cycle of $94{ }^{\circ} \mathrm{C}$ for $5 \mathrm{~min}$; followed by 45 cycles at $95^{\circ} \mathrm{C}$ for $10 \mathrm{~s}$, annealing $60^{\circ} \mathrm{C}$ for $20 \mathrm{~s}$, extension $72{ }^{\circ} \mathrm{C}$ for $20 \mathrm{~s}$; and with a final extension step at $95^{\circ} \mathrm{C}$ for $5 \mathrm{~s}, 65^{\circ} \mathrm{C}$ for $1 \mathrm{~min}$, and $40^{\circ} \mathrm{C}$ for $10 \mathrm{~s}$. The expression of the housekeeping gene $18 \mathrm{~S}$ rRNA was determined as an internal control. Triplicates of each reaction were performed for each sample. Primers used for RT-PCR and qPCR are shown in Table 1. 
Table 2. PCR primers sequence and RNAi nucleotide sequence used in this study.

\begin{tabular}{|c|c|c|}
\hline Subject & Primer Name & Primer Sequence $\left(5^{\prime}-3^{\prime}\right)$ \\
\hline \multirow{2}{*}{ First fragment cloning } & acsl6-F1 & ATGCAGTTTCAGGATTGGTTACGT \\
\hline & acsl6-R1 & CTATACGGATGATTTCCTGTACATC \\
\hline \multirow{2}{*}{$3^{\prime} \mathrm{RACE}$} & acsl6-F2 & CAGGTGAAGGACTTATATTTGCAC \\
\hline & acsl6-F3 & GATGTACAGGAAATCATCCGTATAG \\
\hline \multirow{4}{*}{ 5'RACE } & acsl6-R2 & GCGGAGCGTCTACAGCTCTGATC \\
\hline & acsl6-R3 & ACGTAACCAATCCTGAAACTGCAT \\
\hline & SD1-F & CTTACGCGTGCTAGCCCGGGCTCGAGGCCCAGAATTTGCACAGATTACGTG \\
\hline & SD2-F & GCTCTTACGCGTGCTAGCCCGGGCTCGAGTGTGAAACATTATGTAAGTTGAATACTTTTAC \\
\hline \multirow[t]{4}{*}{ PCR for $5^{\prime}$ flanking sequence cloning } & SD3-F & GCTCTTACGCGTGCTAGCCCGGGCTCGAGTGATGAAGACGTATTCTTAATTTGCTGG \\
\hline & SD4-F & GCTCTTACGCGTGCTAGCCCGGGCTCGAGACTTATAGTTTGAATCAGATTTTATTTTCCAT \\
\hline & SD-R & ACCAACAGTACCGGAATGCCAAGCTTCTTGCCATCTCCTCCAGTGAAAC \\
\hline & EMF1 (5'-biotin labeled) & CATTGGCTGATACATCATCATCAT \\
\hline \multirow{8}{*}{ EMSA probes } & EMR1 (5'-biotin labeled) & САТTTCACСТTTAACCACAGACA \\
\hline & EMF2 & ATTGGCTGATACATCATCATCAT \\
\hline & EMR2 & ATTTCACCTTTAACCACAGACA \\
\hline & RT-acsl6-F & ATGCAGTTTCAGGATTGGTTACGT \\
\hline & RT-acsl6-R & TGCTATCTGCAGTCCTCTCTGGAA \\
\hline & Q-acsl6-F & GATCAGAGCTGTAGACGCTCCGCT \\
\hline & Q-acsl6-R & CCTCAGTGTAAGAGATCCACTGAT \\
\hline & ppar $\gamma-\mathrm{F}$ & AGACATGGTGGACACGCAGACGTT \\
\hline \multirow{7}{*}{ RT-PCR and qPCR } & ppar $\gamma-\mathrm{R}$ & CGCTCTCCTGCATCCTGTAGTTCT \\
\hline & ppara-F & GGGAAAGAGCAGCACGAG \\
\hline & ppar $\alpha-\mathrm{R}$ & GCGTGCTTTGGCTTTGTT \\
\hline & srebp $1-\mathrm{F}$ & CGTCTGCTTCACTTCACTACTC \\
\hline & srebp $1-\mathrm{R}$ & GGACCAGTCTTCATCCACAAA \\
\hline & 18S rRNA & CTGAGAAACGGCTACCATTC \\
\hline & 18S rRNA & GCCTCGAAAGAGACCTGTATTG \\
\hline
\end{tabular}




\subsection{Cloning of acsl6 Gene Promoter and Construction of Deletion Mutants}

Genomic DNA of muscle tissue was extracted from common carp using the standard phenol-chloroform extraction method and was used as a template for cloning the candidate promoter. The 1790-bp upstream sequence of the acsl6 gene was obtained from the genomic sequencing data of common carp. For identifying the core promoter region of acsl6 gene, four promoter fragments (SD1-SD4) were amplified using Transfer-PCR (TPCR) [48] with one of the specific forward primers (SD1-F, SD2-F, SD3-F, and SD4-F; Table 1) and a common reverse primer (SD-R; Table 1) and inserted into pGL3.0 vector (Promega, USA). The upstream sequence in the four insert fragments including SD4, SD3, SD2, and SD1 was of $-1789 \mathrm{bp},-1231 \mathrm{bp},-758 \mathrm{bp}$, and $-198 \mathrm{bp}$ lengths to the putative transcription start site (TSS +1$)$, respectively (Figure 4). These sequences were checked by sequencing in Shanghai Sangon Biotech Co., Ltd. (Shanghai, China).

\subsection{Site-Directed Mutagenesis of acsl6 Core Promoter}

The core promoter sequence of acsl 6 was analyzed by TRANSFAC ${ }^{\circledR}$, MatInspector $^{\circledR}$, and JASPAR ${ }^{\circledR}$. Bingding sites for eleven TFs including FOXO1, SP1, AP1, CDX1, YY1 (two), C/EBP $\alpha$, TBP, SREBP1c, $\operatorname{PPAR} \alpha$, and PPAR $\gamma$ were found in the core promoter (Figure 5). To detect the functions of these predicted TF binding sites on the activity of acsl6 core promoter, site-directed mutation of recombinant plasmids (Table 3) was performed using Muta-directTM site-directed mutagenesis kit (SBS Genetech, Shenzhen, China) as described in the manufacturer's protocol and were verified by DNA sequencing. The influence of TF binding site mutations on the promoter activity of acsl6 was measured by dual-luciferase assay as described below, and the construct SD3 was used as a reference.

Table 3. Primers used for site-directed mutations of transcription factors (TFs) on common carp acsl6 core promoter.

\begin{tabular}{cccc}
\hline TFs & Position & Predicted Element & Mutation Site \\
\hline FOXO1 & -733 & TGGTGTTTTC & TGGTGTTTTTC $\rightarrow \times$ \\
\hline SP1 & -672 & CATTGGCTG & CATTGGCTG $\rightarrow \times$ \\
\hline AP1 & -658 & TCATCATCATC & TCATCATCATC $\rightarrow \times$ \\
\hline CDX1 & -545 & ATTTATA & ATTTATA $\rightarrow \times$ \\
\hline YY1 & -485 & GCCATTTA & GCCATTTA $\rightarrow \times$ \\
\cline { 2 - 4 } & -453 & AAAAATGGCACA & AAAAATGGCACA $\rightarrow \times$ \\
\hline C/EBP $\alpha$ & -474 & CTTTGCAAT & CTTTGCAAT $\rightarrow \times$ \\
\hline TBP & -404 & CTATTAAAAGGGCCA & CTATTAAAAGGGCCA $\rightarrow \times$ \\
\hline SREBP-1 & -343 & GTGTTGTGATG & GTGTTGTGATG $\rightarrow \times$ \\
\hline PPAR $\gamma:$ RXR $\alpha$ & -325 & TCTGTGGTTAAAGGTGAAAT & TCTGTGGTTAAAGGTGAAAT $\rightarrow \times$ \\
\hline PPAR $\alpha: R X R \alpha$ & -323 & TGTGGTTAAAGGTGAA & TGTGGTTAAAGGTGAA $\rightarrow \times$ \\
\hline
\end{tabular}

Notes: The binding sites for TFs are described in Figure 5. The bases underlined are chosen for site-directed mutant (deletion), " $\rightarrow$ " means substitution, and " $x$ " means deletion.

\subsection{Cell Culture, Transfection, and Dual Luciferase Assay}

HEK 293T cells were maintained in high glucose Dulbecco's Modified Eagle Medium (Gluta-MAX DMEM) (Gibco, Life Technologies, New York, NY, USA) containing 10\% fetal bovine serum (Gibco, New York, NY, USA). Cells were transfected using Lipofectamine ${ }^{\circledR}$ LTX Reagent with PLUSTM reagent (Invitrogen, Carlsbad, CA, USA) following the manufacturer's instruction. Briefly, the promoter reporter plasmid (100 ng) and the internal control vector pGL3.0 (0.01 ng) were co-transfected into the cells. The Dual Luciferase Reporter Assay System E2940 (Promega, Madison, WI, USA) was used to measure luciferase activity according to the manufacturer's protocol. Briefly, cells were harvested $24 \mathrm{~h}$ after transfection and treated with $75 \mu \mathrm{L}$ Dual-Glo Luciferase Assay Reagent (Promega, Madison, WI, USA) and incubated at $25{ }^{\circ} \mathrm{C}$ for $10 \mathrm{~min}$. The promoter activity was calculated from the luminescence ratio of firefly/renilla luciferase for each construct. Each group was analyzed three times. 


\subsection{Electrophoretic Mobility Shift Assay (EMSA)}

To investigate the interaction of TFs and the core promoter of the acsl6 gene, the nuclear and cytoplasmic proteins of muscle were extracted with the Beyotime Nuclear Extract Kit (Beyotime, Shanghai, China), followed by quantification with Non-Interference Protein Assay Kit (Sangon, Shanghai, China). The $5^{\prime}$ end biotin-labeled probe (EMF1/EMR1, Table 1) of 364 bp covering TF elements (SP1, AP1, CDX1, YY1, C/EBP $\alpha$, TBP, SREBP1, PPAR $\alpha$, and PPAR $\gamma$ ) was designed and incubated with the muscular proteins. Both the labeled and unlabeled probes in the experiment were synthesized from Shanghai Sangon Biotech Co., Ltd. The EMSA reaction system was performed using the Beyotime Chemiluminescent EMSA Kit (Beyotime Institute of Biotechnology, Shanghai, China) as described in the manufacturer's protocol. The detailed experimental condition of EMSA was according to our previous studies $[10,49]$.

\subsection{Intraperitoneal Injection Experiments}

Two hundred forty healthy juvenile common carp were weighed and randomly distributed into four groups (twelve tanks with 20 fish each tank). After the acclimation, the fish were treated with dimethyl sulfoxide (DMSO, vehicle) (Sigma, St. Louis, MO, USA), PPAR $\alpha$ agonist fenofibrate (Sigma, St. Louis, MO, USA), PPAR $\gamma$ agonist balaglitazone (Sigma, St. Louis, MO, USA), or SREBP1 antagonist betulin (Sigma, St. Louis, MO, USA). These agonists/antagonists were dissolved in 2.5\% DMSO and diluted with $0.65 \% \mathrm{NaCl}$ to obtain a final concentration of $1 \mathrm{mg} / \mathrm{mL}$. All fish were fasted on the day before injection. Before injection, fish were first anesthetized with $0.01 \%$ 2-phenoxyethanol. The control group was treated with $2.5 \% \mathrm{DMSO}$, while the fenofibrate, balaglitazone, and betulin groups were treated with the corresponding agonists/antagonists (1 mg drug per $100 \mathrm{~g}$ fish). The drugs were slowly injected into their abdominal cavity. After the first injection, fish were put back into the corresponding tanks. After $24 \mathrm{~h}$, each group was fed with the formula feed as mentioned above, and 6 days after the first injection, a similar dose of injection was repeated. At $24 \mathrm{~h}$ after the second injection, three fish from each tank (nine fish per group) were anesthetized with 0.01\% 2-phenoxyethanol and muscle tissues were sampled from each fish, frozen in liquid nitrogen, and stored at $-80{ }^{\circ} \mathrm{C}$ before the analyses of acsl6, ppar $\alpha$, ppar $\gamma$, and srebp 1 mRNA expression by qPCR (primers are shown in Table 1).

\subsection{Analysis of Fatty Acids Composition}

Total lipids were extracted from diets and muscle of common carp with a mixture of chloroform/methanol $(v / v, 2: 1)$, followed by fatty acid methyl esters (FAME) using boron trifluoride diethyl etherate (ca. 48\%, Acros Organics, Waltham, MA, USA). FAME were analysed and separated using a gas chromatograph (GC2010-plus, Shimadzu, Japan) as previously described [50]. Briefly, FAME samples were applied using on-column injection, and the oven temperature was programmed from 80 to $250{ }^{\circ} \mathrm{C}$ at a rate of $40{ }^{\circ} \mathrm{C} \mathrm{min}^{-1}$ and held at $210{ }^{\circ} \mathrm{C}$ for $30 \mathrm{~min}$. Individual FAME were identified through comparison with commercial standards (Sigma, St. Louis, MO,) and quantified with CLASS-GC2010-plus workstation (Shimadzu, Kyoto, Japan).

\subsection{Statistical Analysis}

All data were expressed as means \pm standard error of mean (SEM). One-way analysis of variance (ANOVA) followed by Tukey's multiple comparison test was used to analyze the tissue distribution and promoter activity of acsl6 gene. The effects of agonists/antagonists on acsl6, ppar $\alpha$, ppar $\gamma$, and srebp 1 mRNA expression were analyzed by the Student's t-test. $p$ values $<0.05$ were considered statistically significant. All statistical analyses were performed using SPSS v17.0 (SPSS Inc., Michigan Avenue, Chicago, IL, USA).

Supplementary Materials: Supplementary materials can be found at http://www.mdpi.com/1422-0067/21/13/ 4736/s1. 
Author Contributions: D.X., G.N., and Y.L. conceived and designed the experiments. D.X. and Z.H. performed the experiments. D.X., Y.D., and Z.H. analyzed the data. D.X. and Z.H. contributed reagents/materials/analysis tools. D.X., Z.G., and Y.L. wrote the paper. All authors have read and agreed to the published version of the manuscript.

Funding: This work was financially supported by the National Natural Science Foundation of China (NSFC) (31602176) and by Zhongyuan thousand talents plan-leading talents of Zhongyuan science and technology of Henan province (204200510025).

Conflicts of Interest: The authors declare no conflict of interest.

\section{Abbreviations}

\begin{tabular}{|c|c|}
\hline ALA & $\alpha$-linolenic acid (18:3n-3) \\
\hline AP1 & activated protein 1 \\
\hline ARA & arachidonic acid (20:4n-6) \\
\hline CDX1 & caudal type homeobox transcription factor 1 \\
\hline $\mathrm{C} / \mathrm{EBP} \alpha$ & CCAAT enhancer binding protein \\
\hline DHA & docosahexaenoic acid (22:6n-3) \\
\hline EMSA & electrophoresis mobility shift assay \\
\hline EPA & eicosapentaenoic acid (20:5n-3) \\
\hline FAME & fatty acid methyl esters \\
\hline $\mathrm{FO}$ & fish oil \\
\hline FOXO1 & forkhead transcription factor 1 \\
\hline GC & Gas Chromatography \\
\hline HEK & 293T cell human embryonic kidney cell line \\
\hline LA & linoleic acid \\
\hline LC-PUFA & long-chain polyunsaturated fatty acids \\
\hline LXR & liver $X$ receptor \\
\hline $\operatorname{PPAR} \alpha$ & peroxisome proliferator activated receptor $\alpha$ \\
\hline PPAR $\gamma$ & peroxisome proliferator activated receptor $\gamma$ \\
\hline SP1 & stimulatory protein 1 \\
\hline SRE & sterol regulatory element \\
\hline SREBP1c & sterol-regulatory element binding protein $1 \mathrm{c}$ \\
\hline TBP & ATA box binding protein \\
\hline TSS & transcription start site \\
\hline YY1 & Yin Yang 1 \\
\hline
\end{tabular}

\section{References}

1. Shahidi, F.; Ambigaipalan, P. Omega-3 polyunsaturated fatty acids and their health benefits. Annu. Rev. Food Sci. Technol. 2018, 9, 345-381. [CrossRef]

2. Cardoso, C.; Afonso, C.; Bandarra, N.M. Dietary DHA and health: Cognitive function ageing. Nutr. Res. Rev. 2016, 29, 281-294. [CrossRef]

3. Elagizi, A.; Lavie, C.J.; Marshall, K.; DiNicolantonio, J.J.; O’Keefe, J.H.; Milani, R.V. Omega-3 polyunsaturated fatty acids and cardiovascular health: A comprehensive review. Prog. Cardiovasc. Dis. 2018, 61, 76-85. [CrossRef]

4. West, L.; Pierce, S.R.; Yin, Y.; Fang, Z.; Zhou, C.; Bae-Jump, V.L. Docosahexaenoic acid (DHA), an omega-3 fatty acid, inhibits ovarian cancer growth and adhesion. Gynecol. Oncol. 2018, 149, 63. [CrossRef]

5. Setty, B.Y.; Betal, S.G.; Miller, R.E.; Brown, D.S.; Meier, M.; Cahill, M.; Stuart, M.J. Relationship of Omega-3 fatty acids DHA and EPA with the inflammatory biomarker hs-CRP in children with sickle cell anemia. Prostag. Leukotr. Essent. 2019, 146, 11-18. [CrossRef] [PubMed]

6. Agostoni, C.; Bresson, J.L.; Fairweather, T.S.; Flynn, A.; Golly, I.; Korhonen, H.; Moseley, B. Scientific opinion on the tolerable upper intake level of eicosapentaenoic acid (EPA), docosahexaenoic acid (DHA) and docosapentaenoic acid (DPA): EFSA panel on dietetic products, nutrition and allergies (NDA). EFSA. J. 2012, 10, 2815.

7. Tocher, D.R. Omega-3 long-chain polyunsaturated fatty acids and aquaculture in perspective. Aquaculture 2015, 449, 94-107. [CrossRef] 
8. Turchini, G.M.; Torstensen, B.E.; Ng, W.K. Fish oil replacement in finfish nutrition. Rev. Aquac. 2009, 1, $10-57$. [CrossRef]

9. Oboh, A.; Kabeya, N.; Carmona-Antoñanzas, G.; Castro, L.F.C.; Dick, J.R.; Tocher, D.R.; Monroig, Ó. Two alternative pathways for docosahexaenoic acid (DHA, 22: 6n-3) biosynthesis are widespread among teleost fish. Sci. Rep. 2017, 7, 1-10. [CrossRef]

10. Dong, Y.; Zhao, J.; Chen, J.; Wang, S.; Liu, Y.; Zhang, Q.; You, C.; Monroig, Ó.; Tocher, D.R.; Li, Y. Cloning and characterization of $6 / 5$ fatty acyl desaturase $(\mathrm{Fad})$ gene promoter in the marine teleost Siganus canaliculatus. Gene 2018, 647, 174-180. [CrossRef]

11. Chen, C.; Wang, S.; Zhang, M.; Chen, B.; You, C.; Xie, D.; Liu, Y.; Zhang, Q.; Zhang, J.; Monroig, Ó.; et al. miR-24 is involved in vertebrate LC-PUFA biosynthesis as demonstrated in marine teleost siganus canaliculatus. BBA-Mol. Cell Biol. 2019, 1864, 619-628. [CrossRef] [PubMed]

12. Li, Y.; Zhao, J.; Dong, Y.; Yin, Z.; Li, Y.; Liu, Y.; You, C.; Monroig, Ó.; Tocher, D.R.; Wang, S. Sp1 is Involved in Vertebrate LC-PUFA Biosynthesis by Upregulating the Expression of Liver Desaturase and Elongase Genes. Int. J. Mol. Sci. 2019, 20, 5066. [CrossRef] [PubMed]

13. Hamilton, J.A. New insights into the roles of proteins and lipids in membrane transport of fatty acids. Prostaglandins Leukot. Essent. Fatty Acids 2007, 77, 355-361. [CrossRef] [PubMed]

14. Hanebutt, F.L.; Demmelmair, H.; Schiessl, B.; Larqué, E.; Koletzko, B. Long-chain polyunsaturated fatty acid (LC-PUFA) transfer across the placenta. Clin. Nutr. 2008, 27, 685-693. [CrossRef] [PubMed]

15. Schwenk, R.W.; Holloway, G.P.; Luiken, J.J.; Bonen, A.; Glatz, J.F. Fatty acid transport across the cell membrane: Regulation by fatty acid transporters. Prostaglandins Leukot. Essent. Fatty Acids 2010, 82, 149-154. [CrossRef]

16. Ellis, J.M.; Frahm, J.L.; Li, L.O.; Coleman, R.A. Acyl-coenzyme A synthetases in metabolic control. Curr. Opin. Lipidol. 2010, 21, 212. [CrossRef]

17. Lopes-Marques, M.; Cunha, I.; Reis-Henriques, M.A.; Santos, M.M.; Castro, L.F.C. Diversity and history of the long-chain acyl-CoA synthetase (Acsl) gene family in vertebrates. BMC Evol. Biol. 2013, 13, 271. [CrossRef]

18. Fernandez, R.F.; Kim, S.Q.; Zhao, Y.; Foguth, R.M.; Weera, M.M.; Counihan, J.L.; Ellis, J.M. Acyl-CoA synthetase 6 enriches the neuroprotective omega-3 fatty acid DHA in the brain. Proc. Natl. Acad. Sci. USA 2018, 115, 12525-12530. [CrossRef]

19. Fernandez, R.F.; Kim, S.Q.; Ellis, J.M. Acyl-CoA Synthetase 6 Mediates Brain Docosahexaenoic Acid (DHA) Enrichment and Neuroprotection. FASEB J. 2019, 33, 488.

20. Ellis, J.M.; Fernandez, R.F.; Zhao, Y.; Counihan, J.L.; Nomura, D.K.; Chester, J.A. Long-Chain Acyl-CoA synthetase 6 deficiency reduces the omega-3 fatty acid DHA in the brain and disrupts motor control. FASEB J. 2018, 32, 521-539.

21. Shishikura, K.; Kuroha, S.; Matsueda, S.; Iseki, H.; Matsui, T.; Inoue, A.; Arita, M. Acyl-CoA synthetase 6 regulates long-chain polyunsaturated fatty acid composition of membrane phospholipids in spermatids and supports normal spermatogenic processes in mice. FASEB J. 2019, 33, 14194-14203. [CrossRef] [PubMed]

22. Hale, B.J.; Fernandez, R.F.; Kim, S.Q.; Diaz, V.D.; Jackson, S.N.; Liu, L.; Ellis, J.M. Acyl-CoA synthetase 6 enriches seminiferous tubules with the $\omega-3$ fatty acid docosahexaenoic acid and is required for male fertility in the mouse. J. Biol. Chem. 2019, 294, 14394-14405. [CrossRef] [PubMed]

23. Teodoro, B.G.; Sampaio, I.H.; Bomfim, L.H.; Queiroz, A.L.; Silveira, L.R.; Souza, A.O.; Neufer, P.D. Long-chain acyl-CoA synthetase 6 regulates lipid synthesis and mitochondrial oxidative capacity in human and rat skeletal muscle. J. Physiol. 2017, 595, 677-693. [CrossRef] [PubMed]

24. Jung, Y.; Bu, S. Suppression of long chain acyl-CoA synthetase blocks intracellular fatty acid flux and glucose uptake in skeletal myotubes. BBA-Mol. Cell Bio. 2020, 158678. [CrossRef]

25. FAO (Food and Agriculture Organization of the United Nations). The State of World Fisheries and Aquaculture 2016; FAO Fisheries and Aquaculture Department: Rome, Italy, 2016.

26. Yeganeh, S.; Shabanpour, B.; Shabani, A. Comparison of farmed and wild common carp (Cyprinus carpio): Seasonal variations in chemical composition and fatty acid profile. Czech. J. Food Sci. 2012, 30, 503-511. [CrossRef]

27. Zhu, C.; Zhu, L.; Huang, H.; Zhou, C.; Zhang, Z.; Zheng, Z. Comparative Analysis of Muscle Nutritional Components of Wild and Cultivated Rock Carp (Procypris rabaudi). J. Nutr. (Chinese) 2017, 39, 203. [CrossRef]

28. Fujino, T.; Yamamoto, T. Cloning and functional expression of a novel long-chain acyl-CoA synthetase expressed in brain. J. Biochem. 1992, 111, 197-203. [CrossRef] 
29. Malhotra, K.T.; Malhotra, K.; Lubin, B.H.; Kuypers, F.A. Identification and molecular characterization of acyl-CoA synthetase in human erythrocytes and erythroid precursors. Biochem. J. 1999, 344, 135-143. [CrossRef]

30. Lee, E.J.; Kim, H.C.; Cho, Y.Y.; Byun, S.J.; Lim, J.M.; Ryoo, Z.Y. Alternative promotion of the mouse acyl-CoA synthetase 6 (mAcsl6) gene mediates the expression of multiple transcripts with $5^{\prime}$-end heterogeneity: Genetic organization of mAcsl6 variants. Biochem. Biophys. Res. Commun. 2005, 327, 84-93. [CrossRef]

31. Weedon-Fekjaer, M.S.; Dalen, K.T.; Solaas, K.; Staff, A.C.; Duttaroy, A.K.; Nebb, H.I. Activation of LXR increases acyl-CoA synthetase activity through direct regulation of ACSL3 in human placental trophoblast cells. J. Lipid Res. 2010, 51, 1886-1896. [CrossRef]

32. Cao, A.; Li, H.; Zhou, Y.; Wu, M.; Liu, J. Long chain acyl-CoA synthetase-3 is a molecular target for peroxisome proliferator-activated receptor $\delta$ in HepG2 hepatoma cells. J. Biol. Chem. 2010, 285, 16664-16674. [CrossRef] [PubMed]

33. Kan, C.F.; Singh, A.B.; Dong, B.; Shende, V.R.; Liu, J. PPAR $\delta$ activation induces hepatic long-chain acyl-CoA synthetase 4 expression in vivo and in vitro. BBA-Mol. Cell Biol. 2015, 1851, 577-587. [CrossRef] [PubMed]

34. Singh, A.B.; Kan, C.F.; Dong, B.; Liu, J. SREBP2 activation induces hepatic long-chain acyl-CoA synthetase 1 (ACSL1) expression in vivo and in vitro through a sterol regulatory element (SRE) motif of the ACSL1 C-promoter. J. Biol. Chem. 2016, 291, 5373-5384. [CrossRef] [PubMed]

35. Zhao, Z.; Zan, L.; Li, A.; Cheng, G.; Li, S.; Zhang, Y.; Zhang, Y. Characterization of the promoter region of the bovine long-chain acyl-CoA synthetase 1 gene: Roles of E2F1, Sp1, KLF15, and E2F4. Sci. Rep. 2016, 6, 19661. [CrossRef]

36. Soupene, E.; Kuypers, F.A. Multiple erythroid isoforms of human long-chain acyl-CoA synthetases are produced by switch of the fatty acid gate domains. BMC Mol. Biol. 2006, 7, 21. [CrossRef]

37. Soupene, E.; Dinh, N.P.; Siliakus, M.; Kuypers, F.A. Activity of the acyl-CoA synthetase ACSL6 isoforms: Role of the fatty acid Gate-domains. BMC biochem. 2010, 11, 18. [CrossRef]

38. Hisanaga, Y.; Ago, H.; Nakagawa, N.; Hamada, K.; Ida, K.; Yamamoto, M.; Hori, T.; Arii, Y.; Sugahara, M.; Kuramitsu, S.; et al. Structural basis of the substrate-specific two-step catalysis of long chain fatty acyl-CoA synthetase dimer. J. Biol. Chem. 2004, 279, 31717-31726. [CrossRef]

39. O'Malley, B.W.; Towle, H.C.; Schwartz, R.J. Regulation of gene expression in eucaryotes. Annu. Rev. Genet. 1997, 11, 239-275. [CrossRef]

40. Martin, G.; Schoonjans, K.; Lefebvre, A.M.; Staels, B.; Auwerx, J. Coordinate regulation of the expression of the fatty acid transport protein and acyl-CoA synthetase genes by PPAR $\alpha$ and PPAR $\gamma$ activators. J. Biol. Chem. 1997, 272, 28210-28217. [CrossRef]

41. Horton, J.D.; Shah, N.A.; Warrington, J.A.; Anderson, N.N.; Park, S.W.; Brown, M.S.; Goldstein, J.L. Combined analysis of oligonucleotide microarray data from transgenic and knockout mice identifies direct SREBP target genes. Proc. Natl. Acad. Sci. USA 2003, 100, 12027-12032. [CrossRef]

42. Motallebipour, M.; Enroth, S.; Punga, T.; Ameur, A.; Koch, C.; Dunham, I.; Wadelius, C. Novel genes in cell cycle control and lipid metabolism with dynamically regulated binding sites for sterol regulatory element-binding protein 1 and RNA polymerase II in HepG2 cells detected by chromatin immunoprecipitation with microarray detection. FEBS J. 2009, 276, 1878-1890. [CrossRef]

43. Way, J.M.; Harrington, W.W.; Brown, K.K.; Gottschalk, W.K.; Sundseth, S.S.; Mansfield, T.A.; Kliewer, S.A. Comprehensive messenger ribonucleic acid profiling reveals that peroxisome proliferator-activated receptor $\gamma$ activation has coordinate effects on gene expression in multiple insulin-sensitive tissues. Endocrinology 2001, 142, 1269-1277. [CrossRef] [PubMed]

44. Gerhold, D.L.; Liu, F.; Jiang, G.; Li, Z.; Xu, J.; Lu, M.; Doebber, T.W. Gene expression profile of adipocyte differentiation and its regulation by peroxisome proliferator-activated receptor- $\gamma$ agonists. Endocrinology 2002, 143, 2106-2118. [CrossRef] [PubMed]

45. Achouri, Y.; Hegarty, B.D.; Allanic, D.; Becard, D.; Hainault, I.; Ferre, P. Long chain fatty acyl-CoA synthetase 5 expression is induced by insulin and glucose: Involvement of sterol regulatory element-binding protein-1c. Biochimie 2005, 87, 1149-1155. [CrossRef]

46. Xie, D.; Yu, R.; Chen, F.; Lu, R.; Yang, L.; Meng, X.; Nie, G. Effects of dietary LNA/LA ratio on growth, hepatic fatty acid profiles and $\triangle 6 f a d$, elovl5 mRNA expression in common carp (Cyprinus carpio). J. Fish (Chinese) 2017, 41, 757-765. [CrossRef] 
47. Saitou, N.; Nei, M. Then eighbor-joining method: A new method for reconstructing phylogenetic trees. Mol. Biol. Evol. 1987, 4, 406-425. [PubMed]

48. Erijman, A.; Dantes, A.; Bernheim, R.; Shifman, J.M.; Peleg, Y. Transfer-PCR (TPCR): A highway for DNA cloning and protein engineering. J. Struct Biol. 2011, 175, 171-177. [CrossRef]

49. Dong, Y.; Wang, S.; Chen, J.; Zhang, Q.; Liu, Y.; You, C.; Monroig, Ó.; Tocher, D.R.; Li, Y. Hepatocyte nuclear factor $4 \alpha(\mathrm{HNF} 4 \alpha)$ is a transcription factor of vertebrate fatty acyl desaturase gene as identified in marine teleost Siganus canaliculatus. PLoS ONE 2016, 11, e0160361. [CrossRef]

50. Li, Y.; Monroig, Ó.; Zhang, L.; Wang, S.; Zheng, X.; Dick, J.R.; You, C.; Tocher, D.R. Vertebrate fatty acyl desaturase with $\Delta 4$ activity. P. Natl. Acad. Sci. USA. 2010, 107(39), 16840-16845. [CrossRef]

C 2020 by the authors. Licensee MDPI, Basel, Switzerland. This article is an open access article distributed under the terms and conditions of the Creative Commons Attribution (CC BY) license (http://creativecommons.org/licenses/by/4.0/). 